\title{
PATEN SEBAGAI RISET PENDUKUNG YANG RELEVAN DAN UNDANG-UNDANG PENUNJANG PATEN
}

\author{
FAKHRI MUSLIDAR \\ 155100029, 785567908 \\ Fakultas Komputer \\ fakhrimuslidar.student@institusi.ac.id
}

\begin{abstract}
Hak Atas Kekayaan Intelektual adalah hak eksklusif yang diberikan suatu hukum atau peraturan kepada seseorang atau sekelompok orang atas karya ciptanya. Menurut UU yang telah disahkan oleh DPR-RI pada tanggal 21 Maret 1997, HaKI adalah hak-hak secara hukum yang berhubungan dengan permasalahan hasil penemuan dan kreativitas seseorang atau beberapa orang yang berhubungan dengan perlindungan permasalahan reputasi dalam bidang komersial (commercial reputation) dan tindakan / jasa dalam bidang komersial (goodwill).

Definisi paten merupkaan suatu hak khusus yang diberikan oleh suatu negara kepada seorang penemu atau pencipta atas suatu hasil pencapaian atau hasil ciptaan dari penemu itu sendiri yang salahsatunya dibidang teknologi. Hak paten tersebut diatur dalam Pasal 1 Ayat 1 UU mengenai HAK PATEN.

Dari definisi kata paten itu sendiri, konsep paten mendorong inventor untuk membuka pengetahuan demi kemajuan masyarakat dan sebagai gantinya, inventor mendapat hak eksklusif selama periode tertentu. Mengingat pemberian paten tidak mengatur siapa yang harus melakukan invensi yang dipatenkan, sistem paten tidak dianggap sebagai hak monopoli.
\end{abstract}

Kata kunci : eksklusif, HaKI, Komersial. 


\section{A. INTRODUCTION}

Definisi Hak atas Kekayaan Intelektual (HaKI) adalah hak eksklusif yang diberikan suatu hukum atau peraturan kepada seseorang atau sekelompok orang atas karya ciptanya. Menurut UU yang telah disahkan oleh DPR-RI pada tanggal 21 Maret 1997, HaKI adalah hak-hak secara hukum yang berhubungan dengan permasalahan hasil penemuan dan kreativitas seseorang atau beberapa orang yang berhubungan dengan perlindungan permasalahan reputasi dalam bidang komersial (commercial

reputation) dan tindakan / jasa dalam bidang komersial (goodwill).

Dengan begitu obyek utama dari HaKI adalah karya, ciptaan, hasil buah pikiran, atau intelektualita manusia. Kata "intelektual" tercermin bahwa obyek kekayaan intelektual tersebut adalah kecerdasan, daya pikir, atau produk pemikiran manusia (the Creations of the Human Mind) (WIPO, 1988:3). Setiap manusia memiliki memiliki hak untuk melindungi atas karya hasil cipta, rasa dan karsa setiap individu maupun kelompok.

Kita perlu memahami HaKI untuk menimbulkan kesadaran akan pentingnya daya kreasi dan inovasi intelektual sebagai kemampuan yang perlu diraih oleh setiap manusia, siapa saja yang ingin maju sebagai faktor pembentuk kemampuan daya saing dalam penciptaan Inovasi-inovasi yang kreatif.

Berbicara mengenai pahak paten, hak paten adalah hak eksklusif yang diberikan oleh Negara kepada Inventor atas hasil Invensinya di bidang teknologi, yang untuk selama waktu tertentu melaksanakan sendiri Invensinya tersebut atau memberikan persetujuannya kepada pihak lain untuk melaksanakannya.

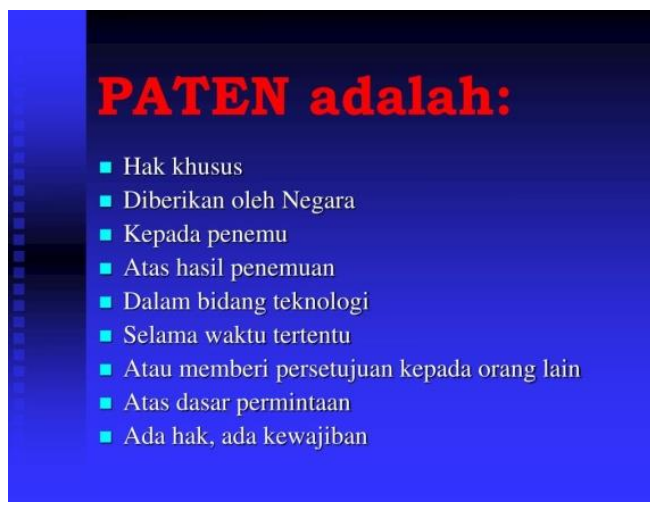

Yang berhak memperoleh Paten adalah Inventor atau yang menerima lebih lanjut hak Inventor yang bersangkutan. Jika suatu Invensi dihasilkan oleh beberapa orang secara bersama-sama, hak atas Invensi tersebut dimiliki secara bersama-sama oleh para inventor yang bersangkutan.Kecuali terbukti lain, yang dianggap sebagai Inventor adalah seorang atau beberapa orang yang untuk 
pertama kali dinyatakan sebagai Inventor dalam Permohonan.

Pihak yang berhak memperoleh Paten atas suatu Invensi yang dihasilkan dalam suatu hubungan kerja adalah pihak yang memberikan pekerjaan tersebut, kecuali diperjanjikan lain. Ketentuan ini berlaku terhadap Invensi yang dihasilkan baik oleh karyawan maupun pekerja yang menggunakan data dan/atau sarana yang tersedia dalam pekerjaannya sekalipun perjanjian tersebut tidak mengharuskannya untuk menghasilkan Invensi.

Inventor diatas berhak mendapatkan imbalan yang layak dengan memperhatikan manfaat ekonomi yang diperoleh dari Invensi tersebut dan dapat dibayarkan:

- Dalam jumlah tertentu dan sekaligus

- Persentase

- Gabungan antara jumlah tertentu dan sekaligus dengan hadiah atau bonus

- Gabungan antara persentase dan hadiah atau bonus

- Bentuk lain yang disepakati para pihak

Pemegang Paten memiliki hak eksklusif untuk melaksanakan Paten yang dimilikinya dan melarang pihak lain yang tanpa persetujuannya untuk :

- Paten-produk: membuat, menggunakan, menjual, mengimpor, menyewakan, menyerahkan, atau

menyediakan untuk dijual

atau disewakan atau

diserahkan produk yang

diberi Paten.

- Paten-proses:

menggunakan proses

produksi yang diberi Paten

untuk membuat barang dan tindakan lainnya.

Dikecualikan dari ketentuan apabila pemakaian Paten tersebut untuk kepentingan pendidikan, penelitian, percobaan, atau analisis sepanjang tidak merugikan kepentingan yang wajar dari Pemegang Paten.

Untuk pengelolaan kelangsungan berlakunya Paten dan pencatatan lisensi, Pemegang Paten atau penerima lisensi suatu Paten wajib membayar biaya tahunan. Paten diberikan atas dasar Permohonan. Setiap Permohonan hanya dapat diajukan untuk satu Invensi atau beberapa Invensi yang merupakan satu kesatuan Invensi. Permohonan diajukan dengan membayar biaya kepada Direktorat Jenderal HKI. Permohonan diajukan secara tertulis dalam bahasa Indonesia kepada Direktorat Jenderal HKI. Sertifikat Paten merupakan bukti hak atas Paten. Paten mulai berlaku pada tanggal diberikan Sertifikat Paten dan berlaku surut sejak Tanggal Penerimaan. 
Paten dapat beralih atau dialihkan baik seluruhnya maupun sebagian karena:

- Pewarisan

- Hibah

- Wasiat

- Perjanjian tertulis

- Sebab lain yang dibenarkan oleh peraturan perundangundangan.

Pengalihan hak tidak menghapus hak Inventor untuk tetap dicantumkan nama dan identitasnya dalam Paten.

\section{B. CONTENT}

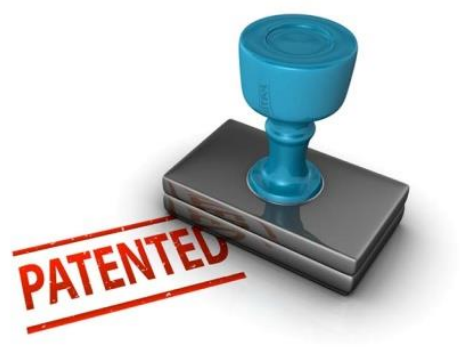

\section{CONTOH STUDY KASUS MENGENAI PATEN :}

Hak paten adalah hak eksklusif yang diberikan oleh Negara atau pemerintah kepada inventor atas hasil invensinya di bidang teknologi, yang untuk selama waktu tertentu melaksanakan sendiri invensinya tersebut atau memberikan persetujuannya kepada pihak lain.

Paten adalah hak khusus yang diberikan negara kepada

$\begin{array}{lrr}\text { penemu atas } & \text { hasil } \\ \text { penemuannya } & & \text { dibidang } \\ \text { teknologi } & \text { atas } & \text { hasil } \\ \text { penelitiannya } & \text { sendiri } & \text { atau } \\ \text { orang lain } & \text { dengan } \\ \text { persetujuannya. }\end{array}$

Sedangkan seseorang atau beberapa orang yang melakukan penelitian dan menemukan suatu temuan (invensi) dalam bidang teknologi dinamakan inventor. Pemegang paten adalah inventor sebagai pemilik paten atau pihak yang menerima hak tersebut dan terdaftar dalam Daftar Umum Paten.

Ada 2 macam sistem pendaftar an Paten yaitu:

- Sistem first to file yaitu memberikan hak paten bagi yang mendaftar pertama atas invensi baru sesuai persyaratan.

- Sistem first to invent adalah sistem yang memberikan hak paten bagi yang menemukan inovasi pertama kali sesuai persyaratan yang telah ditentukan.

Sekarang ini, mengingat perkembangan zaman yang semakin maju, teknologi semakin berkembang pesat, banyak kasus pelanggaran hak 
paten khususnya di bidang industri. Hal tersebut disebabkan karena si penjiplak menginginkan produk yang didistribusikan ke seluruh negara atau seluruh daerahnya dapat diakui di masyakarat dan terutama ingin meraih keuntungan yang besar karena dianggap memiliki kesamaan dengan produk produsen lain. Padahal, hal tersebut memasuki pelanggaran hak paten karena pemilik awal telah mendaftar patennya atas kepemilikan dari hasil ciptaan awal.

Akibat dari kasus tersebut, menimbulkan permasalahan yang panjang bahkan sampai menuju jalur hukum yang mengakibatkan si penjiplak mengalami kerugian yang sangat besar, mulai dari segi keuntungan penjualan sampai pada image atau nama baik si produsen penjiplak tersebut dengan Undang-Undang yang berlaku. Berikut ini akan saya bahas contoh pelanggaran hak paten di bidang industri beserta analisisnya:

Contoh Study Kasus Hak Paten Mesin Motor Bajaj Ditolak di Indonesia

Motor Bajaj merupakan salah satu produk sepeda motor yang dikenal di kalangan masyarakat Indonesia, bahkan desain yang dihasilkan menarik dan terlihat elegan. Namun, tidak disangka hak paten teknologi mesin motor kebanggaan masyarakat India ini menjadi masalah di Indonesia.

Bajaj Auto Limited sebagai produsen motor Bajaj menggugat Ditjen Hak Kekayaan Intelektual (HAKI), Kementerian Hukum dan HAM (Kemenkum HAM). Sebab, permohonan paten untuk sistem mesin pembakaran dalam dengan prinsip empat langkah ditolak dengan alasan sudah dipatenkan terlebih dahulu oleh Honda Giken Kogyo Kabushiki Kaisha.

Kuasa hukum perusahaan Bajaj pun meminta agar hakim pengadilan membatalkan atas penolakan permohonan terhadap kasus tersebut. Kasus tersebut bermula ketika Ditjen Haki menolak permohonan pendaftaran paten Bajaj pada 30 Desember 2009 dengan alasan ketidakbaruan dan tidak mengandung langkah inventif. Atas penolakan tersebut, Bajaj Auto mengajukan banding ke Komisi Banding Paten. Namun Komisi Banding dalam putusannya pada 27 Desember 2010 sependapat dengan Direktorat Paten sehingga kembali menolak pendaftaran paten tersebut. Hal tersebut dikarenakan prinsip motor Bajaj merupakan prinsip yang masih baru berkembang. 
Kesaksian dalam sidang tersebut, satu silinder jelas berbeda dengan dua silinder. Untuk konfigurasi busi tidak menutup kemungkinan ada klaim yang baru terutama dalam silinder dengan karakter lain. Namun, kebaruannya adalah ukuran ruang yang kecil. Dimana harus ada busi dengan jumlah yang sama. Keunggulan dari Bajaj ini adalah bensin yang irit dan memiliki emisi yang ramah lingkungan.

Ditjen HAKI punya catatan tersendiri sehingga menolak permohonan paten ini, yaitu sistem ini telah dipatenkan di Amerika Serikat atas nama Honda Giken Kogyo Kabushiki Kaisha dengan penemu Minoru Matsuda pada 1985. Lantas oleh Honda didaftarkan di Indonesia pada 28 April 2006. Namun dalih ini dimentahkan oleh Bajaj, karena telah mendapatkan hak paten sebelumnya dari produsen negara aslanya, yaitu India.

Berikut adalah aturan-aturan mengenai paten :

Hak Paten Indonesia saat ini diatur dalam UU No. 13 tahun 2016. UU paten ini merupakan UU terbaru yang menggantikan UU paten No. 14 Tahun 2001 karena banyaknya substansi yang perlu ditambahkan maupun diperbaiki.
UNDANG - UNDANG (UU) PATEN REPUBLIK INDONESIA :

- UU Nomor 13 Tahun 2016 tentang Paten

- UU Nomor 14 Tahun 2001 tentang Paten

- Penjelasan UU Nomor 14 Tahun 2001 tentang Paten

PERATURAN PEMERINTAH (PP) BIDANG PATEN

- Peraturan Pemerintah Republik Indonesia Nomor 27 Tahun 2004 tentang Tata Cara Pelaksanaan Paten oleh Pemerintah ditetapkan Tanggal 5 Oktober 2004.

- Peraturan pemerintah ditetapkan Tanggal 5 Oktober 2004

- Peraturan Pemerintah Republik Indonesia Nomor 31 Tahun 1995 tentang Komisi Banding Paten ditetapkan Tanggal 29 Agustus 1995.

- Peraturan Pemerintah Republik Indonesia Nomor 11 Tahun 1993 tentang Bentuk dan Isi Surat Paten ditetapkan Tanggal 22 Februari 1993.

- Peraturan Pemerintah Republik Indonesia Nomor 33 Tahun 1991 tentang Pendaftaran Khusus Konsultan Paten ditetapkan Tanggal 11 Juni 1991.

- Peraturan Pemerintah Republik Indonesia Nomor 45 Tahun 2016 tentang 
Jenis Dan Tarif Atas Penerimaan Negara Bukan Pajak Yang Berlaku Pada Kementerian Hukum dan Hak Asasi Manusia.

\section{PERATURAN PRESIDEN REPUBLIK INDONESIA BIDANG PATEN :}

- Peraturan Presiden

Republik Indonesia No. 76

Tahun $2012 \quad$ Tentang Pelaksanaan Paten Oleh Pemerintah Terhadap Obat Antiviral dan

Antiretroviral.

\section{CONCLUSION}

Hak Atas Kekayaan Intelektual adalah hak eksklusif yang diberikan suatu hukum atau peraturan kepada seseorang atau sekelompok orang atas karya ciptanya. Menurut UU yang telah disahkan oleh DPRRI pada tanggal 21 Maret 1997, HaKI adalah hak-hak secara hukum yang berhubungan dengan permasalahan hasil penemuan dan kreativitas seseorang atau beberapa orang yang berhubungan dengan perlindungan permasalahan reputasi dalam bidang komersial (commercial reputation) dan tindakan / jasa dalam bidang komersial (goodwill).

Hak paten adalah hak eksklusif yang diberikan oleh Negara atau pemerintah kepada inventor atas hasil invensinya di bidang teknologi, yang untuk selama waktu tertentu melaksanakan sendiri invensinya tersebut atau memberikan persetujuannya kepada pihak lain.

Sekarang ini, mengingat perkembangan zaman yang semakin maju, teknologi semakin berkembang pesat, banyak kasus pelanggaran hak paten khususnya di bidang industri. Hal tersebut disebabkan karena si penjiplak menginginkan produk yang didistribusikan ke seluruh negara atau seluruh daerahnya dapat diakui di masyakarat dan terutama ingin meraih keuntungan yang besar karena dianggap memiliki kesamaan dengan produk produsen lain. Padahal, hal tersebut memasuki pelanggaran hak paten karena pemilik awal telah mendaftar patennya atas kepemilikan dari hasil ciptaan awal.

Akibat dari kasus tersebut, menimbulkan permasalahan yang panjang bahkan sampai menuju jalur hukum yang mengakibatkan si penjiplak mengalami kerugian yang sangat besar, mulai dari segi keuntungan penjualan sampai pada image atau nama baik si produsen penjiplak tersebut dengan Undang-Undang yang berlaku. 


\section{DISCUSSION}

Pada dasarnya, undnag-undang perlindungan mengenai Hak Paten yang sudah ada memang dibuat atas dasar perlindungan hak dari seorang penemu agar terlindungi dari banyaknya plagiarism yang ingin memperoleh keuntungan dari tindakan tersebut, namun, beberapa kasus memang masih banyak ditemui pelanggaranpelanggaran serupa dengan berbagai alasan.

Dari kasus diatas dapat dianalisa bahwa perusahaan Bajaj dimungkinkan kurang jeli dalam masalah penggunaan mesin yang aman digunakan untuk konsumen. Walaupun kenyataannya menurut perusahaan Bajaj tersebut menolak atas tuntutan yang diajukan oleh Ditjen HAKI. Sebaiknya jika terbukti bersalah sebaiknya sesegera mungkin diberi solusi untuk perbaikan mesin tersebut agar tidak terjadi masalah seperti pencabutan penjualan dan lainnya.

Namun jika pernyataan berbanding terbalik dari tuduhan awal, sebaiknya perusahaan tersebut menunjukkan bukti fisik yang kuat dan tidak berdiam untuk enggan berkomentar, karena pada asalnya dari negara produsen awal tidak terjadi masalah pada pemesinan tersebut.

Semoga kedepannya tidak terjadi pelanggaran hak paten khususnya bidang industri, dan sebaiknya pencipta suatu teknologi wajib mematenkan hasil karyanya agar tidak terjadi permasalahan yang menyebabkan merugi dan menurunkan image dari perusahaan yang bersangkutan.

\section{E. REFERENCE}

[1] O. M. Febriani and A. S. Putra, "Sistem Informasi Monitoring Inventori Barang Pada Balai Riset Standardisasi Industri Bandar Lampung," J. Inform., vol. 13, no. 1, pp. 90-98, 2014.

[2] A. S. Putra, "Paperplain: Execution Fundamental Create Application With Borland Delphi 7.0 University Of Mitra Indonesia," 2018.

[3] A. S. Putra, "2018 Artikel Struktur Data, Audit Dan Jaringan Komputer," 2018.

[4] A. S. Putra, "ALIAS MANAGER USED IN DATABASE DESKTOP STUDI CASE DB DEMOS."

[5] A. S. Putra, "COMPREHENSIVE SET OF PROFESSIONAL FOR DISTRIBUTE COMPUTING."

[6] A. S. Putra, "DATA ORIENTED RECOGNITION IN BORLAND DELPHI 7.0."

[7] A. S. Putra, "EMBARCADERO DELPHI XE 2 IN GPUPOWERED FIREMONKEY APPLICATION."

[8] A. S. Putra, "HAK ATAS KEKAYAAN INTELEKTUAL DALAM DUNIA TEKNOLOGY BERBASIS REVOLUSI INDUSTRI 4.0.” 
[9] A. S. Putra, "IMPLEMENTASI PERATURAN PERUNDANGAN UU. NO 31 TAHUN 2000 TENTANG DESAIN INDUSTRI BERBASIS INFORMATION TECHNOLOGY."

[10] A. S. Putra, "IMPLEMENTATION OF PARADOX DBASE."

[11] A. S. Putra, "IMPLEMENTATION OF TRADE SECRET CASE STUDY SAMSUNG MOBILE PHONE."

[12] A. S. Putra, "IMPLEMENTATION PATENT FOR APPLICATION WEB BASED CASE STUDI WWW. PUBLIKLAMPUNG. COM."

[13] A "IMPLEMENTATION SYSTEM FIRST TO INVENT IN DIGITALLY INDUSTRY."

[14] A. S. Putra, "MANUAL REPORT \& INTEGRATED DEVELOPMENT

ENVIRONMENT BORLAND DELPHI 7.0."

[15] A. S. Putra, "PATENT AS RELEVAN SUPPORT RESEARCH."

[16] A. S. Putra, "PATENT FOR RESEARCH STUDY CASE OF APPLE. Inc."

[17] A. S. Putra, "PATENT PROTECTION FOR APPLICATION INVENT."

[18] A. S. Putra, "QUICK REPORT IN PROPERTY PROGRAMMING."

[19] A. S. Putra, "REVIEW CIRCUIT LAYOUT COMPONENT
REQUIREMENT ON ASUS NOTEBOOK."

[20] A. S. Putra, "REVIEW TRADEMARK PATENT FOR INDUSTRIAL TECHNOLOGY BASED 4.0."

[21] A. S. Putra, "TOOLBAR COMPONENT PALLETTE IN OBJECT ORIENTED PROGRAMMING."

[22] A. S. Putra, "WORKING DIRECTORY SET FOR PARADOX 7."

[23] A. S. Putra, "ZQUERY CONNECTION

IMPLEMENTED

PROGRAMMING STUDI CASE PT. BANK BCA Tbk."

[24] A. S. Putra, D. R. Aryanti, and I. Hartati, "Metode SAW (Simple Additive Weighting) sebagai Sistem Pendukung Keputusan Guru Berprestasi (Studi Kasus: SMK Global Surya)," in Prosiding Seminar Nasional Darmajaya, 2018, vol. 1, no. 1, pp. 85-97.

[25] A. S. Putra and O. M. Febriani, "Knowledge Management Online Application in PDAM Lampung Province," in Prosiding International conference on Information Technology and Business (ICITB), 2018, pp. 181-187.

[26] A. S. Putra, O. M. Febriani, and B. Bachry, "Implementasi Genetic Fuzzy System Untuk Mengidentifikasi Hasil Curian Kendaraan Bermotor Di Polda Lampung," SIMADA (Jurnal Sist. Inf. dan Manaj. Basis Data), vol. 1, no. 1, pp. 21-30, 2018.

[27] A. S. Putra, H. Sukri, and K. 
Zuhri, "Sistem Monitoring

Realtime Jaringan Irigasi Desa (JIDES) Dengan Konsep Jaringan Sensor Nirkabel," IJEIS (Indonesian J. Electron. Instrum. Syst., vol. 8, no. 2, pp. 221-232.

[28] D. P. Sari, O. M. Febriani, and A. S. Putra, "Perancangan Sistem Informasi SDM Berprestasi pada SD Global Surya," in Prosiding Seminar Nasional Darmajaya, 2018, vol. 1, no. 1, pp. 289-294. 